\title{
Penggunaan Antibiotik Profilaksis Bedah pada Sectio Cesarea di RSUD Arifin Achmad Provinsi Riau
}

\author{
M. Yulis Hamidy ${ }^{1,2}$, Dina Fauzia ${ }^{2}$, Dimas P. Nugraha ${ }^{2}$, M. Imam Muttaqien ${ }^{3}$
}

\begin{abstract}
Cesarean section is a high risk operation for the development of surgical site infection. Routine prophylaxis with antibiotic may reduce this risk. Antibiotic administrations in presurgery and postsurgery are widely used to avoid and to treat surgical site infection. The purpose of this study was to evaluate the administration of prophylactic antibiotics for cesarean section at the Arifin Achmad Hospital, Riau Province. This study included 485 patients who had been underwent cesarean section for one year period (January $1^{\text {st }}-$ December $31^{\text {st }} 2014$ ). Data were collected using patient's medical record. The study showed that prophylactic antibiotic was given to $43.7 \%$ of the subjects. All of the prophylactic subjects received seftriaxon as prophylactic antibiotic. About $75.0 \%$ antibiotic was given $<60$ minutes before incision. All of the drugs were administered by intravenous route. It can be concluded that there are some inappropriate use of prophylactic antibiotics. The greatest inappropriateness is inappopriate duration and indication of prophylactic antibiotic.
\end{abstract}

Keywords: prophylactic antibiotic, cesarean section, surgical site infection

Pemberian antibiotik profilaksis merupakan bagian dari pencegahan infeksi. Antibiotik yang diberikan pada pasien bedah bertujuan untuk mengurangi jumlah koloni bakteri, mengurangi jumlah inokulum kontaminasi sehingga menurunkan risiko infeksi atau sebagai terapi apabila sudah dalam keadaan infeksi sebelumnya. Pada tindakan profilaksis, antibiotik diberikan sebelum terdapat tanda-tanda infeksi. Untuk mencapai optimasi pemberian antibiotik profilaksis, terdapat beberapa hal yang menjadi pertimbangan pada pemberiannya, yaitu perlu tidaknya pemberian terapi profilaksis, jenis antibiotik yang akan diberikan, cara pemberian antibiotik, waktu pemberian antibiotik dan lamanya antibiotik tersebut diberikan. ${ }^{1,2}$

Infeksi daerah operasi merupakan salah satu masalah dalam penanganan pasca bedah. Insidensinya menduduki peringkat kedua sebagai penyebab infeksi nosokomial yang berdampak pada peningkatan morbiditas, mortalitas, dan biaya

\footnotetext{
${ }_{1}$ Penulis untuk korespondensi; Jalan Diponegoro No. 1 Pekanbaru, 28111

e-mail: yulis_hamidy@yahoo.com

2 Bagian Farmakologi Fakultas Kedokteran Universitas Riau

3 Fakultas Kedokteran Universitas Riau
}

pengobatan. Insiden infeksi luka operasi bervariasi antara 2-20\% dari intervensi dan bergantung pada jenis operasinya. ${ }^{3}$ Di Amerika Serikat insidensinya sebesar 2,6\% meskipun telah diterapkan standar sterilisasi dan desinfeksi, penyaringan udara di kamar operasi dan pemberian antibiotik profilaksis. Hal ini berkaitan dengan meningkatnya populasi dengan risiko tinggi seperti usia lanjut dan populasi dengan penyakit penyerta seperti diabetes melitus, gagal ginjal kronik dan lain-lain. ${ }^{1}$

Berbagai pedoman antibiotik profilaksis bedah telah dipublikasikan, aspek yang menjadi perhatian dari pedoman tersebut menyangkut indikasi, pilihan antibiotik, dosis optimal, waktu dan lama pemberian, serta cara pemberian. Menurut The Scottish Intercollegiate Guidelines Network (SIGN) guideline on antibiotic prophylaxis in surgery (SIGN 45) tahun 2008, antibiotik profilaksis bedah harus tetap dengan prinsip bahwa antibiotik yang digunakan tersebut harus didukung oleh bukti keefektifannya, meminimalkan pengaruh antibiotik tersebut terhadap flora bakteri normal pasien, meminimalkan efek samping antibiotik terhadap pasien, dan meminimalkan efek antibiotik terhadap kekebalan tubuh pasien. ${ }^{4}$ 
Sectio cesarea merupakan salah satu tindakan pembedahan yang tergolong pembedahan bersihkontaminasi (clean-contaminated), dan pemberian antibiotik profilaksis bedah sangat direkomendasikan. ${ }^{4}$ Pemberian antibiotik profilaksis bedah pada setiap pembedahan bersihkontaminasi terbukti efektif dalam menurunkan angka kejadian infeksi luka operasi. Efektivitas antibiotik profilaksis bedah sangat tergantung pada konsentrasi antibiotik di daerah insisi, dan setidaknya mencapai konsentrasi hambat minimal. Oleh karena itu, pilihan antibiotik, dosis antibiotik, waktu dan lama pemberian, serta cara pemberian antibiotik menjadi faktor penentu keberhasilan tindakan profilaksis tersebut.

Penelitian ini bertujuan untuk menentukan pola dan ketepatan penggunaan antibiotik profilaksis bedah pada pasien yang menjalani sectio cesarea sebagai usaha pengendalian resistensi terhadap antibiotik sekaligus mengurangi angka kejadian infeksi luka operasi (ILO) pasca sectio cesarea dan menekan biaya pengobatan di rumah sakit.

\section{METODE}

Penelitian ini merupakan studi deskriptif dengan menggunakan data sekunder yang bersumber dari rekam medik pasien yang menjalani sectio cesarea di RSUD Arifin Ahmad Provinsi Riau Periode 1 Januari 2014 - 31 Desember 2014. Data dikumpulkan dari seluruh rekam medik pasien yang menjalani pembedahan sectio cesarea di RSUD Arifin Ahmad Provinsi Riau pada periode tersebut. Data yang diambil meliputi karakteristik/data demografi (inisial nama pasien, usia/tanggal lahir, nomor rekam medik, jenis kelamin, berat badan, tanggal mulai rawat inap), hasil pemeriksaan laboratorium (leukosit, ureum, kreatinin, SGOT, SGPT, bilirubin), diagnosis pasien, deskripsi tindakan sectio cesarea (jam mulai pembedahan, lama pembedahan, jumlah perdarahan intraoperatif), dan penggunaan antibiotik profilaksis bedah (jenis antibiotik, dosis, jalur pemberian, jam pemberian, penambahan antibiotik profilaksis intraoperatif, lama pemberian).

Untuk menilai ketepatan penggunaan antibiotik profilaksis bedah pada sectio cesarea dilakukan dengan menggunakan Kriteria Gyssens yang meliputi indikasi, dosis, rute pemberian dan lama penggunaan.

\section{HASIL}

Selama periode 1 Januari 2014 - 31 Desember 2014 terdapat 685 pasien yang menjalani sectio cesarea di RSUD Arifin Ahmad Provinsi Riau. Sebanyak 200 pasien dari jumlah tersebut dieksklusi karena tidak sesuai dengan kriteria subjek penelitian, sehingga hanya 485 pasien yang dilanjutkan dalam pengolahan dan analisis data.

Pada penelitian didapatkan usia rata-rata subjek penelitian adalah 29,8 tahun $(29,8 \pm 6,2)$ dengan usia median 29,0 tahun. Usia tertinggi subjek penelitian adalah 53 tahun dan usia terendah 17 tahun. Berdasarkan sifat pembedahannya sebagian besar subjek penelitian $(72,0 \%)$ menjalani pembedahan emergensi/cito dan berdasarkan teknik insisi yang dilakukan sebagian besar menggunakan teknik pfannenstiel $(71,1 \%)$. Untuk lama pembedahan seluruh subjek penelitian menjalani pembedahan $\leq 3$ jam. Selanjutnya untuk teknik anestesi yang digunakan sebagian besar $(85,8 \%)$ dengan anestesi regional (spinal). Karakteristik pasien secara lengkap dapat dilihat pada Tabel 1 berikut.

Tabel 1. Karaktersitik pasien penelitian $(n=485)$

\begin{tabular}{ccc}
\hline Karakteristik & Jumlah & Persentase \\
\hline Sifat pembedahan & & \\
$\bullet$ Emergensi/cito & 349 & 72,0 \\
$\bullet$ Elektif & 100 & 20,6 \\
$\bullet$ Tidak ada data & 36 & 7,4 \\
Teknik insisi & & \\
$\bullet$ Pfannenstiel & 345 & 71,1 \\
$\bullet$ Midline & 133 & 27,4 \\
$\bullet$ Tidak ada data & 7 & 1,4 \\
Lama pembedahan & & \\
$\bullet \leq 3$ jam & 485 & 100,0 \\
$\bullet>3$ jam & 0 & 0,0 \\
Teknik anestesi & & \\
$\bullet$ Umum & 63 & 13,0 \\
$\bullet$ Spinal & 416 & 85,8 \\
$\bullet$ Tidak ada data & 6 & 1,2 \\
\hline
\end{tabular}


Antibiotik profilaksis bedah pada pasien sectio cesarea diberikan kepada 212 orang subjek penelitian (43,7\%), sedangkan sebanyak 273 subjek tidak mendapat antibiotik profilaksis bedah $(56,3 \%)$. Sebanyak 212 orang subjek yang mendapat antibiotik profilaksis bedah, seluruhnya menggunakan seftriakson. Sementara untuk waktu pemberian antibiotik profilaksis bedah, sebanyak $75,0 \%$ antibiotik profilaksis diberikan $\leq 60$ menit sebelum insisi pembedahan dilakukan. Tidak ada satupun subjek yang mendapat antibiotik intraoperatif. Untuk lama pemberian antibiotik, seluruh pasien mendapat antibiotik profilaksis lebih dari 24 jam dan pemberian antibiotik profilaksis pada sectio cesarea seluruhnya diberikan secara parenteral (intravena). Secara lengkap pola penggunaan antibiotik profilaksis pada sectio cesarea dapat dilihat pada Tabel 2 berikut.

Tabel 2. Pola penggunaan antibiotik profilaksis pada seksio sesaria $(\mathrm{n}=212)$

\begin{tabular}{|c|c|c|}
\hline \multirow{2}{*}{$\begin{array}{l}\text { Parameter } \\
\text { Jenis antibiotik }\end{array}$} & Jumlah & Persentase \\
\hline & & \\
\hline - Seftriakson & 212 & 100,0 \\
\hline Waktu pemberian antibiotik & & \\
\hline - $\leq 60$ menit & 159 & 75,0 \\
\hline - $>60$ menit & 53 & 25,0 \\
\hline Antibiotik intraoperatif & & \\
\hline - Ya & 0 & 0,0 \\
\hline - Tidak & 212 & 100,0 \\
\hline Lama pemberian antibiotik & & \\
\hline$\bullet 24$ jam & 0 & 0,0 \\
\hline - $>24$ jam & 212 & 100,0 \\
\hline Rute pemberian antibiotik & & \\
\hline -Intravena & 212 & 100,0 \\
\hline -Oral & 0 & 0,0 \\
\hline
\end{tabular}

Sebanyak 212 subjek yang menjalani seksio sesaria, sebagian besar subjek tidak diberikan antibiotik profilaksis bedah (56,3\%), hanya $43,7 \%$ saja yang mendapat antibiotik profilaksis bedah tersebut. Artinya, ketepatan penggunaan antibiotik profilaksis bedah berdasarkan indikasi pemberiannya hanya sebesar $43,7 \%$, sedangkan ketepatan pemilihan antibiotik profilaksis bedah adalah sebesar $100 \%$ karena seluruh subjek mendapat seftriakson sebelum menjalani sectio cesarea.

Sebanyak $75 \%$ subjek penelitian mendapat antibiotik profilaksis bedah dalam waktu $\leq 60$ menit sebelum insisi pembedahan. Dengan demikian ketepatan penggunaan antibiotik profilaksis bedah pada penelitian ini adalah sebesar $75 \%$. Namun bila dilihat berdasarkan lama pemberian antibiotik profilaksis bedah, seluruh pasien (100\%) mempunyai kategori tidak tepat karena mendapat antibiotik profilaksis bedah $>24$ jam. Rute pemberian antibiotik profilaksis bedah pada penelitian ini seluruhnya (100\%) melalui intravena dan dikategorikan tepat.

\section{PEMBAHASAN}

Telah dilakukan penelitian terhadap 485 orang subjek penelitian yang menjalani sectio cesarea di RSUD Arifin Achmad Provinsi Riau, Pekanbaru periode 1 Januari 2014 - 31 Desember 2014. Usia rata-rata dari subjek penelitian ini adalah 29,8 tahun dengan nilai median 29,0 tahun dan rentang usia 17-53 tahun. Hasil ini sama dengan penelitian serupa oleh Francis et al (2013) yang mendapatkan nilai median usia subjek penelitian adalah 29,0 tahun. ${ }^{5}$ Suatu penelitian meta analisis yang dilakukan oleh Zhang et al (2015) juga mendapatkan hasil yang sama dengan penelitian ini yaitu subjek penelitian yang mempunyai usia rata-rata 29,9 tahun untuk kelompok kontrol dan 30,3 tahun untuk kelompok eksperimental. ${ }^{6}$ Namun hasil ini sedikit berbeda dengan penelitian yang dilakukan oleh Ristic et al (2010) yang dilakukan pada subjek dengan usia ratarata 32 tahun dan rentang usia 18-43 tahun. ${ }^{7}$ Usia 18-34 tahun merupakan usia reproduktif bagi seorang perempuan, sedangkan pada usia e" 35 tahun umumnya perempuan sudah menggunakan alat kontrasepsi atau sudah dilakukan kontrasepsi mantap sehingga angka persalinan akan semakin menurun termasuk persalinan dengan sectio cesarea. ${ }^{8}$

Hasil penelitian juga memperlihatkan bahwa berdasarkan usianya terdapat subjek yang berisiko tinggi (terdapat subjek dengan usia 17 dan 53 tahun). Usia terlalu muda dan terlalu tua merupakan faktor risiko baik untuk kehamilannya maupun untuk tindakan sectio cesarea yang dilakukan. Sementara 
pada subjek penelitian di Eropa didapatkan risiko faktor usia yang lebih aman (usia terendah 18 tahun dan usia tertinggi 43 tahun). ${ }^{7}$

Berdasarkan sifat pembedahannya sebagian besar subjek menjalani sectio cesarea yang bersifat emergensi dan hanya $20,6 \%$ yang menjalani pembedahan elektif. Hasil yang hampir sama juga didapatkan pada penelitian Francis et al, yaitu subjek yang menjalani sectio cesarea elektif sebesar 17,6$18,6 \% .{ }^{5}$ Sifat pembedahan ini dipengaruhi oleh indikasi dilakukannya sectio cesarea sehingga juga akan menentukan pemberian antibiotik pada subjek tersebut.

Durasi pembedahan yang dialami seluruh subjek penelitian kurang dari 3 jam. Hasil serupa juga ditunjukkan oleh penelitian Francis et al dimana nilai median dari durasi sectio cesarea pada penelitian yang dilakukannya adalah selama 42 menit dan penelitian Zhang et al dengan rata-rata lama sectio cesarea adalah 38,35 menit. ${ }^{5,6}$ Sementara penelitian yang dilakukan oleh Wloch et al (2012) mendapatkan durasi pembedahan sectio cesarea selama 40-55 menit. ${ }^{9}$ Sectio cesarea merupakan tindakan pembedahan yang bersifat bersihkontaminasi (clean-contaminated). Semakin lama tindakan pembedahan dilakukan maka akan semakin besar risiko untuk terkontaminasi, sehingga pemberian antibiotik profilaksis bedah sangat direkomendasikan. ${ }^{4}$ Pemberian antibiotik profilaksis bedah pada setiap pembedahan bersih-kontaminasi terbukti efektif dalam menurunkan angka kejadian infeksi luka operasi. ${ }^{10}$

Teknik anestesi yang digunakan sebagian besar adalah dengan anestesi spinal (85,8\%), hanya 13,0\% yang menjalani anestesi umum. Penelitian lain menunjukkan bahwa penggunaan teknik anestesi umum pada sectio cesarea sedikit sekali digunakan, seperti pada penelitian Francis et al, pasien yang menggunakan teknik anestesi umum jauh lebih sedikit yaitu hanya $0,9 \%$ dan penelitian Zhang et al sebesar 3,42\% dari subjek penelitiannya. ${ }^{5,6}$ Kondisi ini disebabkan karena teknik anestesi umum mempunyai risiko yang lebih besar jika dibandingkan dengan teknik anestesi spinal.

Sebanyak 43,7\% subjek penelitian mendapatkan antibiotik profilaksis. Hasil yang hampir sama juga didapatkan pada penelitian Wardoyo dkk yang mendapatkan $40 \%$ sectio cesarea diberi antibiotik profilaksis. ${ }^{11}$ Jenis antibiotik yang digunakan sebagai antibiotik profilaksis pada penelitian ini hanya satu jenis yaitu seftriakson. Hasil ini mirip dengan penelitian Ristic et al yang menjelaskan bahwa seftriakson merupakan antibiotik profilaksis yang sering digunakan. Pada penelitian Ristic et al ini juga didapatkan hasil bahwa ada sebagian subjek penelitian yang mendapat lebih dari satu jenis antibiotik profilaksis. ${ }^{7}$

Sebagian besar antibiotik profilaksis $(75,0 \%)$ diberikan kurang dari 60 menit sebelum insisi dilakukan. Kondisi ini sesuai dengan rekomendasi dari The American College of Obstetricians and Gynecologists bahwa antibiotik profilaksis diberikan dalam waktu 60 menit sebelum sectio cesarea dilakukan. ${ }^{12}$ Tidak ada subjek penelitian yang mendapat antibiotik intraoperatif. Hal ini sesuai dengan hasil lama pemberian antibiotik yang seluruhnya lebih dari 24 jam, sehingga tidak diperlukan lagi pemberian antibiotik selama pembedahan dilakukan. Seluruh antibiotik profilaksis yang diberikan kepada subjek penelitian dilakukan secara intravena, sehingga obat dapat segera berada dalam plasma untuk dapat menghasilkan efek pencegahan terhadap kemungkinan terjadinya infeksi selama sectio cesarea dilakukan.

\section{KESIMPULAN}

Ketepatan penggunaan antibiotik profilaksis pada penelitian ini ditinjau dari beberapa aspek. Penggunaan antibiotik profilaksis sudah baik berdasarkan pemilihan obat, waktu dan rute pemberian. Namun, ketepatannya masih kurang jika ditinjau dari aspek indikasi dan lama pemberian obat.

\section{UCAPAN TERIMA KASIH}

Peneliti menyampaikan ucapan terima kasih kepada Lembaga Penelitian dan Pengabdian kepada Masyarakat Universitas Riau yang telah mendanai penelitian ini dan kepada Direktur RSUD Arifin Achmad Provinsi Riau yang telah memfasilitasi terlaksananya penelitian ini. 


\section{DAFTAR PUSTAKA}

1. Chen K, Setiawan B, Pohan HT. Penggunaan antibiotik untuk profilaksis pada pembedahan. Dalam: Mansjoer A, Sudoyo AW, Alwi I, Rinaldi I, Harimurti K, Laksmi PW, dkk. Kedokteran perioperatif: evaluasi dan tata laksana di bidang ilmu penyakit dalam. Jakarta: Internal Publishing; 2007.p.60-72.

2. Van der Meer JMW, Van Kasteren M. Improving prescribing in surgical prophylaxis. In: Gould IM, Van der Meer JWM, editors. Antibiotic policies: theory and practice. New York: Kluwer academic Publishers; 2005.p.185-95.

3. Rudilla MC, Rodríguez JPD, Santana AR, Molist MG, Gómez MAO, Conde JAM, et al. Perioperative pharmacological treatment recommendations. CIR ESP. 2009;86(3):130-8.

4. Scottish Intercollegiate Guidelines Network. Antibiotic prophilaxis in surgery; A national clinical guideline, 2008.

5. Francis C, Mumford M, Strand ML, Moore ES, Strand EA. Timing of prophylactic antibiotic at cesarean section: a double-blinded, randomized trial. Journal of Perinatology.2013;33:759-62.

6. Zhang C, Zhang L, Liu X, Zhang L, Zeng Z, Li $\mathrm{L}$, et al. Timing of antibiotic prophylaxis in elective caesarean delivery: a multi-center randomized controlled trial and meta-analysis. PLoS ONE 2015;10(7): e0129434. doi:10.1371/ journal.
7. Ristic S, Miljkovic B, Vezmar S, Stanojevic D. Are local clinical guidelines useful in promoting rational use of antibiotic prophylaxis in Caesarean delivery? Pharm World Sci.2010; 32:139-45.

8. Prawirohardjo S, Wiknjosastro GH. Ilmu kandungan. Edisi ketiga cetakan pertama. Jakarta: PT Bina Pustaka; 2011.

9. Wloch C, Wilson J, Lamagni T, Harrington P, Charlett A, Sheridan A. Risk factors for surgical site infection following caesarean section in England : results from a multicentre cohort study. BJOG; 2012.

10.Keping C, Jiawei L, Qingfang K, Wang C, Nanyuan Y. Risk factor for surgical site infection in a teaching hospital: a prospective study at 1.138 patient. Patient Preference \& adherence. 2015;9: 1171-7.

11.Wardoyo EH, Tjoa E, Ocvyanty D, Moehario LH. Infeksi luka operasi (ILO) di bangsal kebidanan dan kandungan RSUPN Cipto Mangunkusumo (RSCM). CDK-216.2016;41(5).

12.Committee on Obstetric Practice. Committee Opinion No. 465: Antimicrobial prophylaxis for cesarean delivery - Timing of administration. Obstet Gynecol 2010 Sep; 116:791. 